$\xi=-1$

\title{
Comparative performance analysis of one rank cuckoo search technique based optimization for automatic generation control of interconnected power systems
}

\author{
N. Manoharan ${ }^{1 *}$, Subhransu Sekhar Dash ${ }^{2}$, Raghuraman Sivalingam ${ }^{3}$, Dheeraj P. R. ${ }^{2}$ \\ ${ }^{1}$ Research scholar, Department of Electricl Engineering,Sathyabama University, Chennai,India \\ ${ }^{2}$ Department of Electrical Engineering,SRM University, Chennai,India \\ ${ }^{3}$ Department of Electrical Engineering, Velammal Engineering College, Chennai \\ *Corresponding author E-mail: skmraghuraman@gmail.com
}

\begin{abstract}
This paper presents a one rank cuckoo search optimization technique is proposed to design classical PID Controllers for Automatic Generation Control (AGC) of interconnected power systems. This method is proposed based on the original cuckoo search method. It was found in original cuckoo search the convergence speed is comparative lesser in reaching optimal solutions. To overcome the above mentioned problem one rank cuckoo search algorithm has been proposed which uses a bound by best solution technique to get the valid dimension so as to improve the system performance and rate of convergence. The proposed approach is applied to a four area hydrothermal system in which area- 1 and area- 2 are steam reheat power plant and area- 3 and area- 4 are hydro power plant. The controller gains are derived using original cuckoo search and one rank cuckoo search methods. The superiority of the proposed approach is compared with the results obtained with original cuckoo search algorithm.
\end{abstract}

Keywords: Automatic Generation Control (AGC); Cuckoo Search; Interconnected Power System; One Rank Cuckoo Search; Classical PID Controller.

\section{Introduction}

The main objective of the Automatic Generation Control (AGC) is to ensure that the system is in equilibrium working condition which means that there is a balance established between powergenerated and power demand. Any mismatch between the above two powers due to rise and fall of load demand will result in the deviation of real and reactive power balance, which in turn leads to the deviation of system frequency and tie-line power interchange from their scheduled value.

Apart from the main objective, there are other objectives that AGC ensures. They are [1]:

1) Steady state frequency change should be zero due to step change in the load.

2) The change in tie-line power flow following a step load change should be zero.

3) The transient frequency and time errors should be small.

4) During an emergency, area in need of power should get assistance from other areas.

In order to achieve the above control objectives, a conventional Proportional Integral Derivative (PID) controller is used. PID controller is considered owing to its simplicity in implementation and its better dynamic response. But, their performance deteriorate when the complexity in the system increases due to disturbances in the load variation boiler dynamics [2], [3].

Over the last few decades, various controllers like Integral (I), Proportional Integral (PI), Integral Derivative (ID), PID [4], adaptive controller [5], robust controller [6], intelligent controllers using neural network [7], fuzzy logic [8-10], fractional order controller [11], internal mode controller [12], hybrid neuro-fuzzy controller [13] have been implemented to prevent frequency and tie-line power flow deviation.

Several control strategies have also been proposed to ensure the normal working of the power system. Meta-heuristic optimization techniques such as particle swarm optimization (PSO) [14], genetic algorithm (GA) [15], biogeography-based optimization (BBO) [16], [17], krill herd algorithm (KHA) [18], teaching learning based optimization (TLBO) $[19,20]$, bacteria foraging optimization (BFOA) [21], gravitational search algorithm (GSA) [22], hybrid PSO-pattern search (hPSO-PS) algorithm [23], hybrid FAPS [24], Tabu search algorithm (TSA) [25], quasi-oppositional harmony search algorithm (QOHSA) [26], [27], BAT algorithm [28], backtracking search algorithm (BSA) [29] have been proposed.

It is observed from the literature survey that the implementation of newly proposed optimization techniques for the frequency and tieline power control yielded good results than the older optimization techniques. Therefore, the field of AGC always welcomes the application of recently proposed optimization techniques.

One Rank Cuckoo Search (ORCS) Algorithm in the year 2013 is developed by Ahmed tweaking the rules associated with the cuckoo search optimization for better results. This optimization technique has been implemented in the field of feed forward neuralnetwork training [30] and optimal reactive powerdispatch [31]. The optimization technique successfully yielded better results in the above mentioned fields. This proves that ORCS algorithm is efficient and outperforms other meta-heuristic algorithms.

In view of the above discussion, a maiden attempt has been made in this project for the application of ORCS for the AGC of multiarea interconnected power system. The ability of ORCS is demonstrated against four area interconnected hydro-thermal power sys- 
tem. The superiority of ORCS is shown by comparing the results with cuckoo search.

\section{Mathematical model of the power system}

\subsection{System under study}

A four area hydro-thermal power system interconnected with tielines is the system understudy. The power system consists of many control areas. The power system consists of many control areas with complex and multi-variable structures. Also, they consists of different control blockswhich are either non-linear time variant or non-minimum phase system. Each area is associated withstudy. The power system consists of many control areas with complex and multi-variable structures. Also, they consists of different control blocks which are either non-linear time variant or non-minimum phase system. Each area is associated with individual system frequency and tie-line power flow. The detailed Power System scheme is shown in Fig. 1. The parameter values for both thermal and hydro power system is given in Appendix.

Frequency and tie-line power flow in any power system is achieved by two different control actions

I.e. primary speed control and supplementary or secondary control. Primary control is achieved by selecting proper $R_{i}$ and $B_{i}$ values and they cannot be influenced much. Hence, usually secondary control method is used for control actions.

Secondary control action is achieved by varying the PID parameters in each area. It results in minimizing the Area Control Error (ACE). The Area Control Error is a linear combination of frequency and tie-line power given by:

$\mathrm{e}_{\mathrm{i}}(\mathrm{t})=\mathrm{ACE}_{\mathrm{i}}=\mathrm{B}^{\mathrm{a}}{ }_{\mathrm{i}} \Delta \mathrm{f}^{\mathrm{a}}{ }_{\mathrm{i}}+\Delta \mathrm{P}^{\mathrm{a}}{ }_{\text {Tie } \mathrm{i}}$

In Eq. (1) $\mathrm{i}=1,2,3,4 ; \mathrm{a}=1$

Where $\mathrm{B}_{\mathrm{i}}^{\mathrm{a}}$ 's are the frequency bias parameters, $\Delta \mathrm{f}^{\mathrm{a}}{ }_{\mathrm{i}}$ 's are the frequency deviations and $\Delta \mathrm{P}^{\mathrm{a}}$ Tie iare the tie-line power flow out of areas.

ACE is considered to be the controlled parameter which determines any mismatch between power generation and power demand. Hence, the selection of objective function is done by either taking a few points from the time response or the entire time response i.e. Integral Criterion.

In literature, there are four commonly used integral performance criterion. They are Integral Square Error (ISE), Integral Absolute Error (IAE), Integral Time multiplies of Square Error (ITSE) and Integral Time Absolute Error (ITAE). ISE returns answer by integrating the square of the error and IAE returns the value by taking the absolute value of the error. Hence, both of these are not accurate. ITSE provides large control output for a sudden change in load. Hence, it is not a good choice for controller design. ITAE reduces peak overshoot and the result is obtained by integrating the product of absolute error time over time.

Therefore, ITAE is considered as the objective function in this paper. It is defined as:

$$
J=\int_{0}^{t}{ }_{\text {simulation }} t \cdot\left(\left|\Delta f_{i}^{a}{ }_{i}\right|+\left|\Delta P_{\text {Tie- }-i-k}^{a}\right|\right) d t
$$

Where $\Delta f^{a}{ }_{i}$ is the change in frequency in corresponding area $\mathrm{i}$, $\Delta P_{T i e-i-k}^{a}$ is the change in tie line power connecting between area $\mathrm{i}$ and area $\mathrm{k}$.

\section{Cuckoo search}

Cuckoo search is a meta-heuristic technique, created by Xin-She Yang and Suash Deb in 2009. CS was enlivened by the behaviour of a few cuckoo species, in blend with the Lévy flights irregular strolls. Cuckoos are getting researchers' advantage in light of their forceful generation methodology. A few bird types lay their eggs in homes of other host winged creatures (different species), and may evacuate others eggs to build the likelihood of their own eggs. CS idealized rules can be summarized as:

i). Each cuckoo lays an egg at any given moment, and dumps its egg in an arbitrarily picked nest/home.

ii). The best homes with high calibre of eggs will persist to the following steps.

iii). The number of accessible host homes is settled, and the egg laid by a cuckoo is found by the host winged creature with a likelihood, where the host feathered creature can either discard the egg, or desert the home and assemble a totally new home.

While investigating new arrangements, it is important to control the Levy flights random walks, to stay away from extensive moves, making the arrangements hop outside of the search space. A stage measure consider that is characterized by the size of the issue of intrigue ought to be utilized for this reason.

\section{One rank cuckoo search}

The proposed technique, one rank cuckoo search (ORCS), applies two behavioural revisions to the first cuckoo technique, in expectations to enhance the rate of convergence, and thus accomplish a superior execution and precision. These practices are characterized in the accompanying subsections.

a) One Rank (Combined Evaluation)

The original cuckoo search technique creates new homes utilizing Levy flights (exploration stage) and assesses their fitness, then replaces a small amount of homes (exploitation stage) and assesses and positions their fitness yet again. Rather, the proposed technique creates new arrangements utilizing Levy flights, replaces a small amount of them, lastly assesses and positions their fitness without a moment's delay. This conduct permits a more moderate utilization of the function assessments, by consolidating the new arrangements produced by the exploration and exploitation stages before assessing them, and henceforth devouring (population measure) assessments per emphasis by the proposed technique against assessments by the first technique.

A one rank factor $r_{\text {orf }}$ is started by 1 , to permit the proposed technique to consolidate every one of the explorations and exploitations, until it neglects to discover better homes for tor cycles, to trigger a progressive reduction of the one rank proportion as in 4.1 , where $t_{c}$ is the cycle number and $D_{m}$ is the quantity of objective function measurement.

$r_{\text {orf }}^{t_{c}+1}=\left(r_{\text {orf }}^{t_{c}} \times 1\right)-0.5 / D_{m}$

\section{b) Bound by Best Solutions}

The proposed technique upholds the respectability over an out of requirements arrangement by supplanting its invalid measurements by the comparing measurements drawn from arbitrarily chosen answers among the present best answers.

A ratio of the supplanted measurements is using the present best arrangements discovered up until this point, and the rest is by and large arbitrarily drawn by further investigating the searchspace. A bound by best ratio $r_{b b b}$ is given as indicated in eq. (4)

$\mathrm{r}_{\mathrm{bbbr}}=1-1 / \sqrt{\mathrm{D}_{\mathrm{m}}}$

The proposed ORCS calculation presented one more parameter, one rank ratio update trigger $t_{o r}$, along with the two parameters utilized by the first CS calculation, populace estimate $\mathrm{N}$ and abandon rate $\mathrm{p}_{\mathrm{a}}$. This parameter has not been optimized to choose the best performing setting; however the preparatory tests experienced amid the calculation improvement, exhibited cold-heartedness in this parameter to majorly affect the calculation execution. 


\section{Simulation and results}

The block diagram shown in Fig. 1 is developed in Simulink and executed using MATLAB code files for Cuckoo Search and One
Rank Cuckoo Search optimization techniques. 1\% step load change is considered in the results and the outputs for frequency and tie line power flows are plotted for both Cuckoo Search and One Rank Cuckoo Search as shown in Figs. 2-8.

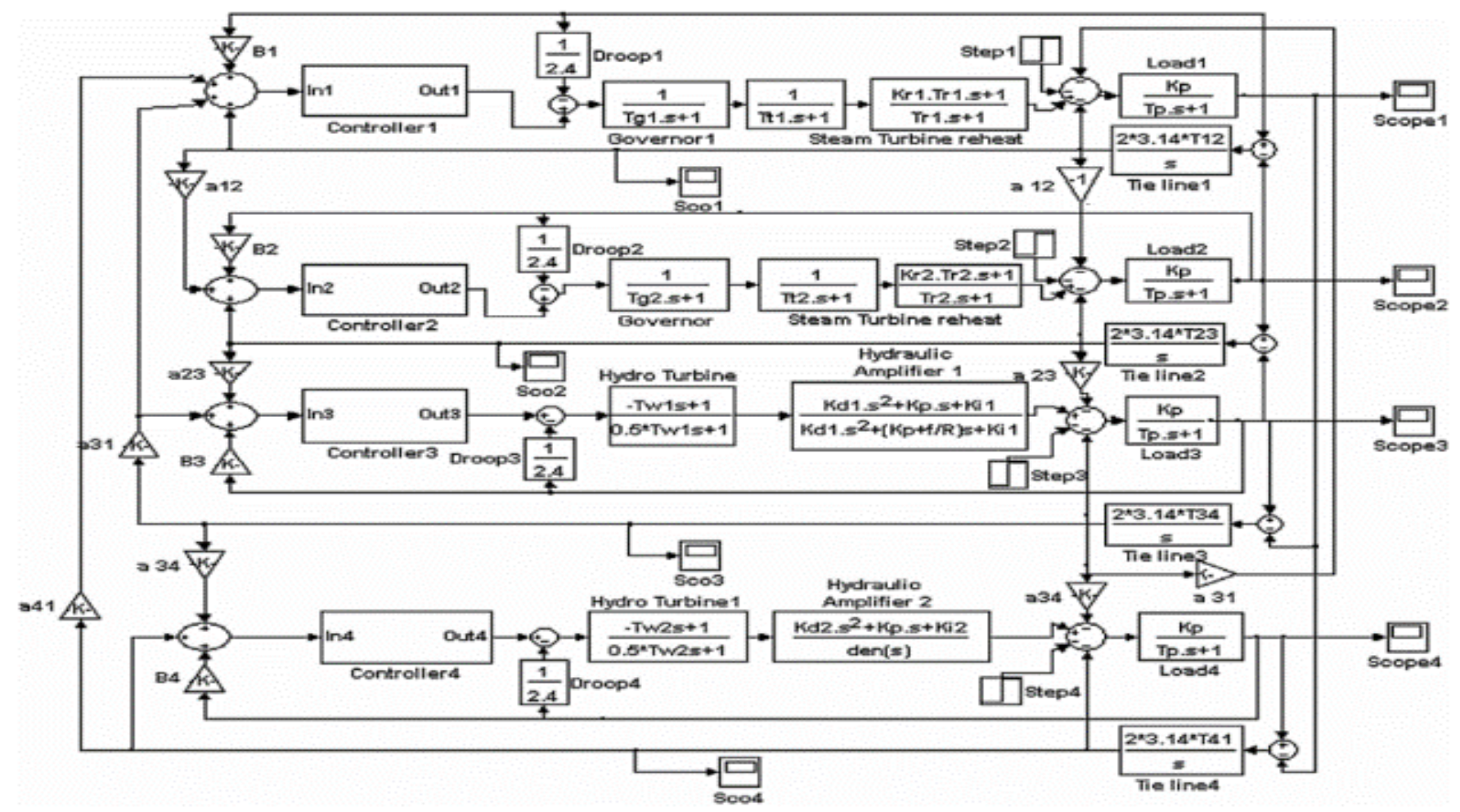

Fig. 1: Matlab/Simulink Model for 4-Area Hydro-Thermal Reheat Interconnected System.

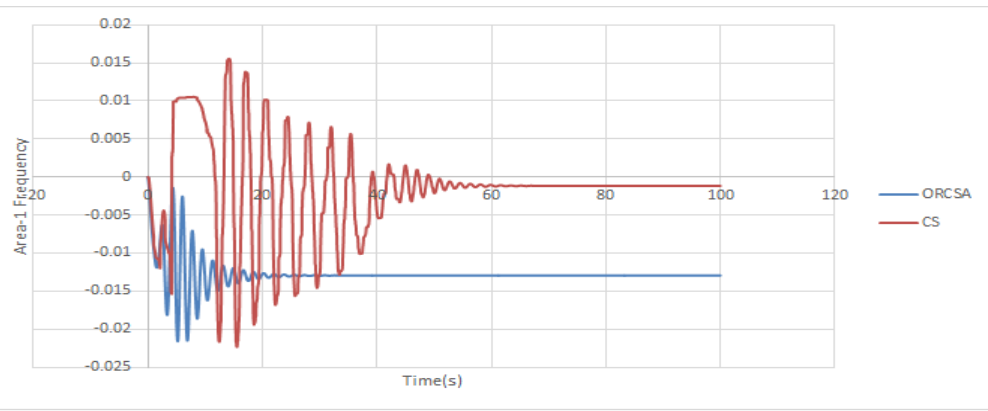

Fig. 2: Frequency Deviation Inarea-1.

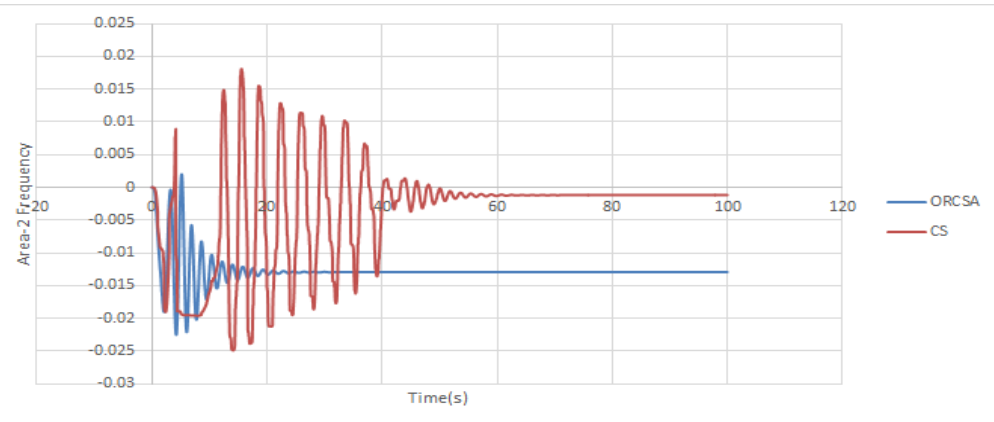

Fig. 3: Frequency Deviation Inarea-2. 


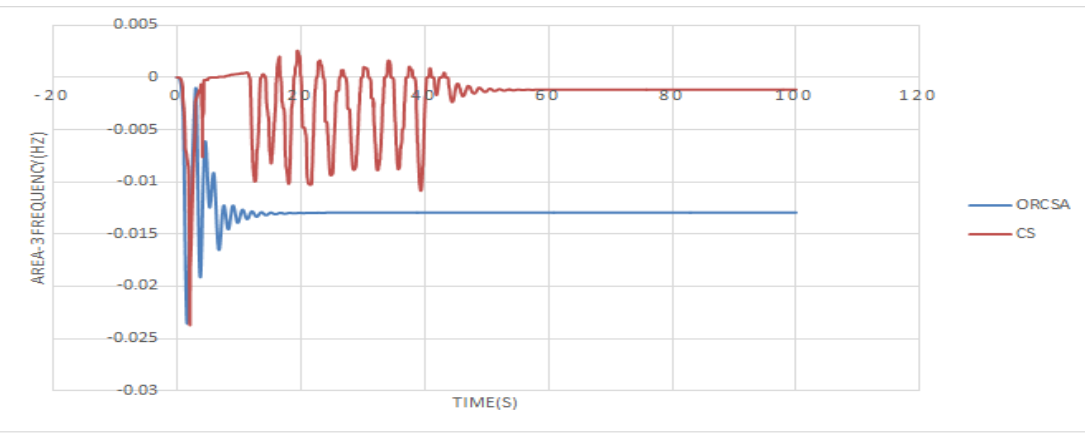

Fig. 4: Frequency Deviation Inarea-3.

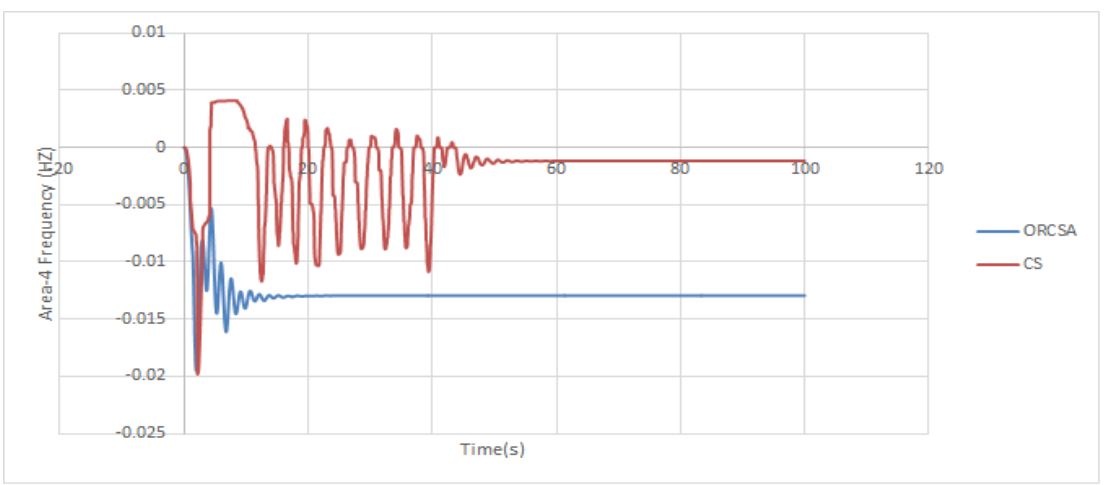

Fig. 5: Frequency Deviation Inarea-4.

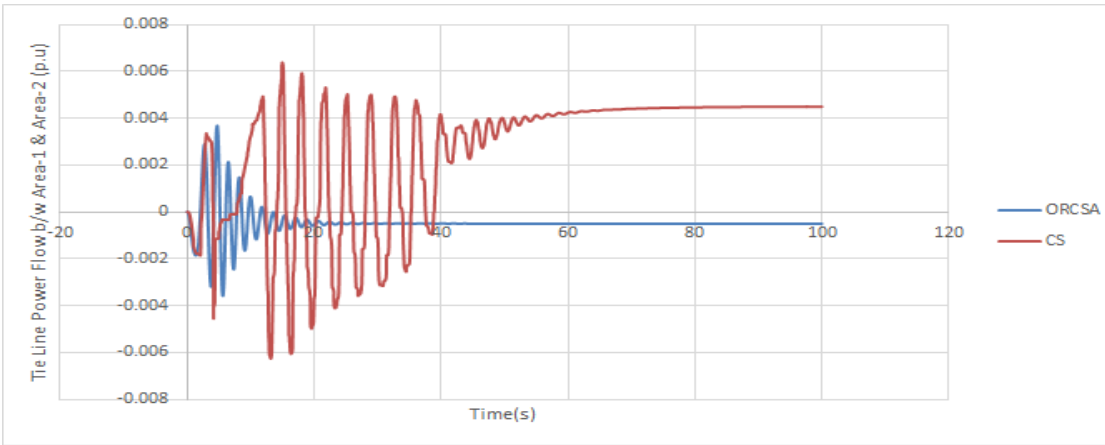

Fig. 6: Change in Tie-Line Power Flow between Area-1\&2.

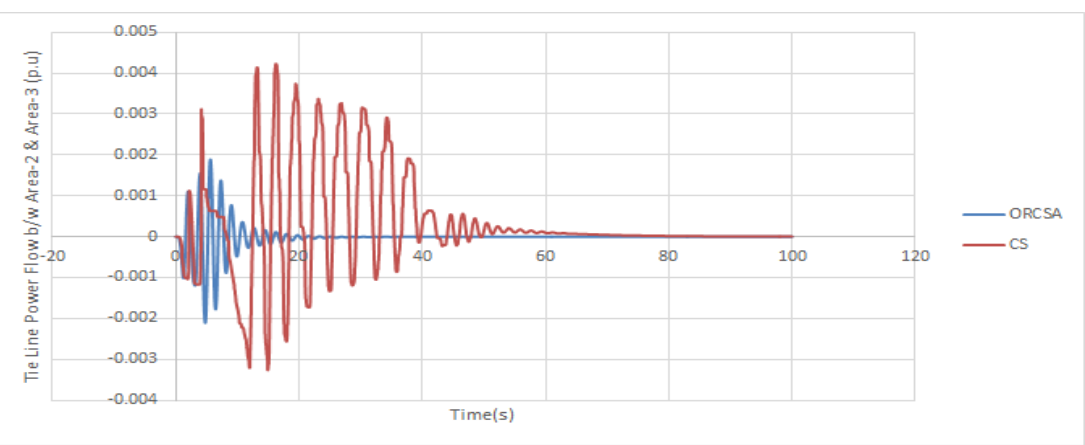

Fig. 7: Change in Tie-Line Power Flow between Area-2\&3.

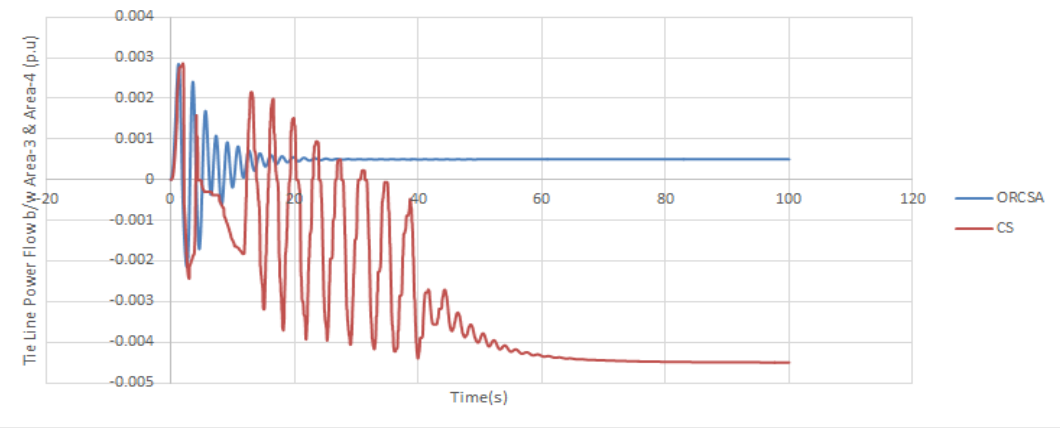

Fig. 8: Change in Tie-Line Power Flow between Area-3\&4. 
From the above figures, it can be concluded that the performance of ORCS trumps the performance of CS as the settling time of ORCS based AGC is very less than CS based AGC for the system under study.

The average controller values after running the system in MATLAB/SIMULINK environment for 15 different times is as given in Table 1:

Table 1: Average Controller Values for Cs and ORCS

\begin{tabular}{lll}
\multicolumn{3}{c}{ Table 1: Average Controller Values for Cs and ORCS } \\
\hline Controller Parameters & Cuckoo Search & One Rank Cuckoo Search \\
\hline $\mathrm{K}_{\mathrm{P} 1}$ & 1.3180 & 1.3922 \\
$\mathrm{~K}_{\mathrm{I} 1}$ & 1.2401 & 1.3404 \\
$\mathrm{~K}_{\mathrm{D} 1}$ & 2 & 1.7537 \\
$\mathrm{~K}_{\mathrm{P} 2}$ & 1.0319 & 1.9961 \\
$\mathrm{~K}_{\mathrm{I} 2}$ & 1.1833 & 1.1233 \\
$\mathrm{~K}_{\mathrm{D} 2}$ & 2 & 1.7317 \\
$\mathrm{~K}_{\mathrm{P} 3}$ & 2 & 1.5502 \\
$\mathrm{~K}_{\mathrm{I} 3}$ & 2 & 1.3188 \\
$\mathrm{~K}_{\mathrm{D} 3}$ & 2 & 1.6797 \\
$\mathrm{~K}_{\mathrm{P} 4}$ & 2 & 1.7127 \\
$\mathrm{~K}_{\mathrm{I} 14}$ & 2 & 1.4168 \\
$\mathrm{~K}_{\mathrm{D} 4}$ & 2 & 1.1280 \\
\hline
\end{tabular}

The range of the controller values for developing both the optimization techniques were considered to be in the range of 0 to 2 . Hence, if we observe the controllers value, we can see that most of the controller values in Cuckoo Search is showing the threshold value suggesting that the cuckoo search method is fairly shorthanded to handle it. But, the observation of controller values for One Rank Cuckoo Search shows that the values of control parameters are not saturated and they are well within the limits. This again concludes that ORCS is better than its predecessor Cuckoo Search.

In order to test the dynamic performance of ORCS method, the system under study is subjected to different load conditions using ORCS optimization technique and the results obtained are as shown in Table II.

Table 2: Comparison of Dynamic Performance

\begin{tabular}{|c|c|c|c|c|c|}
\hline \multicolumn{2}{|c|}{ Step Load Pertubation } & $1 \%$ SLP & $3 \%$ SLP & $5 \%$ SLP & $10 \%$ SLP \\
\hline \multirow{8}{*}{$\begin{array}{l}\text { Settling } \\
\text { times } \\
(\mathrm{sec})\end{array}$} & $\Delta \mathrm{f}_{1}$ & 18.62 & 20.20 & 21.79 & 22.32 \\
\hline & $\Delta \mathrm{f}_{2}$ & 18.47 & 19.83 & 22.69 & 23.15 \\
\hline & $\Delta \mathrm{f}_{3}$ & 18.47 & 19.52 & 22.18 & 23.9 \\
\hline & $\Delta \mathrm{f}_{4}$ & 18.28 & 19.76 & 21.98 & 23.33 \\
\hline & $\Delta \mathrm{P}_{\text {tie-12 }}$ & 22.66 & 24.56 & 26.12 & 28.84 \\
\hline & $\Delta \mathrm{P}_{\text {tie-23 }}$ & 22.93 & 23.50 & 28.10 & 30.64 \\
\hline & $\Delta \mathrm{P}_{\text {tie-34 }}$ & 22.62 & 24.73 & 26.58 & 30.81 \\
\hline & $\Delta \mathrm{P}_{\text {tie-41 }}$ & 22.89 & 24.41 & 27.77 & 29.26 \\
\hline
\end{tabular}

\section{Conclusion}

In this paper a new type of meta-heuristic algorithm has been proposed for automatic generation control of multi-area interconnected power systems to guarantee steady and acceptable operation of energy systems. In such manner, present day heuristic procedures, for example, Cuckoo Search (CS) and One Rank Cuckoo Search (ORCS) technique have been connected for AGC of interconnected power systems. Design and performance evaluation of CS and ORCS optimized PID) controller for Automatic Generation Control (AGC) of an interconnected power system is presented.

From the above results, it is evident that the performance of ORCS is better than its predecessor cuckoo search. So, it can be said that ORCS can successfully be used for AGC purposes as it gives better convergence.

\section{Appendix}

Nominal parameters of the system investigated are:
$f=60(\mathrm{~Hz}) ; B_{1}=0.3483, B_{2}=0.3827, B_{3}=0.3692(\mathrm{pu} \mathrm{Hz}) ; D_{1}$

$=D_{3}=0.015, D_{2}=0.016(\mathrm{pu} \mathrm{Hz}) ; 2 H_{1}=0.1667,2 H_{2}=0.2017$,

$2 H_{3}=0.1247,\left(\right.$ pu s) $R_{1}=3.0, R_{2}=2.73, R_{3}=2.82(\mathrm{~Hz} / \mathrm{pu}) ; T_{g 1}$

$=0.08, T_{g 2}=0.06, T_{g 3}=0.07(\mathrm{~s}) ; T_{t 1}=0.4, T_{t 2}=0.44, T_{t 3}=0.3(\mathrm{~s})$;

$K_{r 1}=K_{r 2}=K_{r 3}=0.5 ; T_{r 1}=T_{r 2}=T_{r 3}=10(\mathrm{~s}), T_{12}=0.2, T_{23}=0.12, T_{31}$

$=0.25(\mathrm{pu} / \mathrm{Hz}), P_{R 1}=2000 \mathrm{MW}, P_{R 2}=4000 \mathrm{MW}, P_{R 3}=8000$ MW.

\section{References}

[1] Ranjan Kumar Mallick, Manoj Kumar Debnath, fahimulHaque, RasmiRanjan Rout, Application of Grey Wolves based optimization technique in multi-area Automatic Generation Control, ICEEOT2016.

[1] J. Talaq, F. Al-Basri, Adaptive fuzzy gain scheduling for load frequency control, IEEE Trans. Power Syst. 14 (February (1)) (1999) https://doi.org/10.1109/59.744505.

[2] P. Aravindan, M.Y. Sanavullah, Fuzzy logic based automatic load frequency control of two area power system with GRC, Int. J. Comput. Intell. Res. 5 (1) (2009)37-44.

[3] L.C. Saikia, J. Nanda, S. Mishra, Performance comparison of several classical controllers in AGC for multi-area interconnected thermal system, Int. J. Electr.Power Energy Syst. 33 (2011) 394-401.

[4] Y. Oysal, A comparative study of adaptive load frequency controller designs in power system with dynamic neural networks models, Energy Convers.Manage. $46 \quad$ (2005) 2656-2668 https://doi.org/10.1016/j.ijepes.2010.08.036.

[5] D. Rerkpreedapong, A. Hasanovic, A. Feliachi, Robust load frequency control using genetic algorithms and linear matrix inequalities, IEEE Trans. Power Syst. 18 (2) (2003) 855-861. https://doi.org/10.1016/j.enconman.2004.12.010.

[6] S. Prakash, S.K. Sinha, Simulation based neuro-fuzzy hybrid intelligent PI control approach in four-area load frequency control of interconnected power system, Appl. Soft Comput. 23 (2014) 152164. https://doi.org/10.1109/TPWRS.2003.811005.

[7] H. Bevrani, P.R. Daneshmand, Fuzzy logic based load frequency control concerning high penetration of wind turbines, IEEE Syst. J. 6 (1) (2012) 173-180. https://doi.org/10.1016/j.asoc.2014.05.020.

[8] H.A. Yousel, K.A.L. Kharusi, M.H. Albadi, N. Hosseinzadeh, Load frequency control of a multi-area power system: an adaptive fuzzy logic approach, IEEE Trans. Power Syst. 29 (4) (2014) 1822-1830. https://doi.org/10.1109/JSYST.2011.2163028.

[9] H. Yousef, Adaptive fuzzy logic load frequency control of multiarea power system, Int. J. Elect. Power Syst. Res. 68 (2015) 384395. https://doi.org/10.1109/TPWRS.2013.2297432.

[10] M.I. Alomoush, Load frequency control and automatic generation control using fractional order controllers, Electr. Eng. Springer 91 (2010) 357-368. https://doi.org/10.1016/j.ijepes.2014.12.074.

[11] S. Saxsena, Y.V. Hote, Load frequency control in power system via internal model control scheme and model order reduction, IEEE Trans. Power Syst. 28 (3) (2013) 2749-2757. https://doi.org/10.1007/s00202-009-0145-7.

[12] S.B. Shyree, N. Kamaraj, Hybrid Neuro Fuzzy approach for automatic generation control in restructured power system, Int. J. Electr. $\begin{array}{lllll}\text { Power Energy } & \text { Syst. } & 74 & \text { (2016) } & \text { 274-285 }\end{array}$ https://doi.org/10.1109/TPWRS.2013.2245349.

[13] H. Shayeghi, A. Jalili, H.A. Shayanfar, Multi-stage fuzzy load frequency control using PSO, Energy Convers. Manage. 49 (2008) 2570-2580. https://doi.org/10.1016/j.ijepes.2015.05.029.

[14] H. Golpira, H. Bevrani, A framework for economic load frequency control design using modified multi-objective load frequency control, Electr. Power Compon. Syst. 42 (8) (2014) 788-797. https://doi.org/10.1016/j.enconman.2008.05.015.

[15] D. Guha, P.K. Roy, S. Banerjee, Optimal design of superconducting magnetic energy storage based multi-area hydro-thermal system using biogeography based optimization, in: Proc. 2014 IEEE Fourth Int. Conf. Emerging Application of Information Technology (EAIT-2014), ISI Kolkata, 2014, pp. 52-57. https://doi.org/10.1080/15325008.2014.893545.

[16] D. Guha, P.K. Roy, S. Banerjee, Study of dynamic responses of an interconnected two-area all thermal power system with governor and boiler nonlinearities using BBO, in: Proc. 2015 third Int. Conf. ComputerCommunication Control Information Technology (C3IT- 
2015), Academy of Technology, 2015, pp. 1-6. https://doi.org/10.1109/EAIT.2014.27.

[17] D. Guha, P.K. Roy, S. Banerjee, Application of Krill Herd algorithm for optimum design of load frequency controller for multiarea power system network with generation rate constraint, in: 4th Int. Conf. on Frontiers in Intelligent Computing: Theory and Applications (FICTA 2015), 404, Springer, NIT-Durgapur, 2015, pp. 245-257. https://doi.org/10.1109/C3IT.2015.7060122.

[18] R.K. Sahu, T.S. Gorripotu, S. Panda, Automatic generation contro of multi-area power systems with diverse energy sources using Teaching Learning Based Optimization Algorithm, Eng. Sci. Technol. Int. J. 19 (2016) 113-134.

[19] A.K. Barisal, Comparative performance analysis of teaching learning basedoptimization for automatic load frequency control of multi-source power system, Int. J. Electr. Power Energy Syst. 66 (2015) 67-77. https://doi.org/10.1016/j.jestch.2015.07.011.

[20] J. Nanda, S. Mishra, L.C. Saikia, Maiden application of bacterial foraging based optimization technique inmulti-area automatic generation control, IEEE Trans.Power Syst. 24 (2) (2009) 602-609. https://doi.org/10.1016/j.ijepes.2014.10.019.

[21] R.K. Sahu, S. Panda, S. Padhan, Optimal gravitational search algorithm for automatic generation control of an interconnected power system, Ain Shames Eng. J. 5 (3) (2014) 721-733. https://doi.org/10.1109/TPWRS.2009.2016588.

[22] R.K. Sahu, S. Panda, G.T.C. Sekhar, A novel hybrid PSO-PS optimized PI-controller for AGC in multi-area interconnected power systems, Int. J. Electr.Power Energy Syst. 64 (2015) 880-893. https://doi.org/10.1016/j.asej.2014.02.004.

[23] R.K. Sahu, S. Panda, S. Padhan, A hybrid firefly algorithm and pattern search techniques for automatic generation control of multi-are power system, Int. J. Electr. Power Energy Syst. 64 (2015) 9-23. https://doi.org/10.1016/j.ijepes.2014.08.021.

[24] Z. Al-Hamouz, N. Al-Musabi, H. Al-Duwaish, S. Al-Baiyat, On the design of variable structure load frequency controllers by tabu search algorithm:application to nonlinear interconnected models, Electr. Power Compon. Syst.33 (11) (2005) 1253-1267. https://doi.org/10.1016/j.ijepes.2014.07.013.

[25] C.K. Shiva, V. Mukherjee, A novel quasi-oppositional harmony search algorithm for AGC optimization of three-area multi-unit power system after deregulation, Eng. Sci. Technol. Int. J. 19 (2016) 395-420. https://doi.org/10.1080/15325000590951735.

[26] C.K. Shiva, V. Mukherjee, A novel quasi-oppositional harmony search algorithm for automatic generation control of power system, $\begin{array}{lllll}\text { Appl. Soft } & \text { Comput. } 35 & \text { (2015) 749-765. }\end{array}$ https://doi.org/10.1016/j.jestch.2015.07.013.

[27] S.M. Abd-Elazim, E.S. Ali, Load frequency controller design via BAT algorithmfor nonlinear interconnected power system, Int. J. Electr. Power Energy Syst.77 (2016) 166-177. https://doi.org/10.1016/j.asoc.2015.05.054.

[28] D. Guha, P.K. Roy, S. Banerjee, Application of backtracking search algorithm inload frequency control of multi-area interconnected power system, Ain ShamsEng. J. (2016). in press. https://doi.org/10.1016/j.ijepes.2015.11.029.

[29] EhsanValian, ShahramMohanna and Saeed Tavakoli, Improved Cuckoo Search algorithm for Feed-forward neural network training, International Journal of Artificial Intelligence \& Applications (IJAIA), Vol.2, No.3, July 2011

[30] Nguyen HuuThien An, Vo Ngoc Dieu, ThangTrung Nguyen and Vo TrungKien, One Rank Cuckoo Search

[31] Algorithm for Optimal Reactive Power Dispatch, N. H. T. An et al. / GMSARN International Journal 9 (2015) 73 - 82. 